\title{
Center for Renewable Energy and Alternative Transportation Technologies (CREATT)
}

Final Report

Thomas J. Mackin, Ph.D.

Professor of Mechanical Engineering

California Polytechnic State University

San Luis Obispo, CA 93405

805.756.1406

tmackin@calpoly.edu 


\section{Table of Contents}

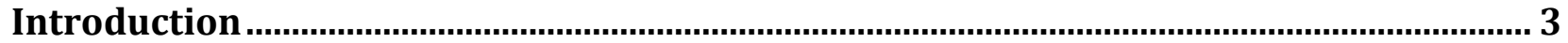

Battery Testing Laboratory …….............................................................................. 3

Compressed Air Energy Storage .........................................................................................

CAES Study Goals and Current Planned Scope:_............................................................................ 4

Test Platform Description: ...................................................................................................................................... 4

Aircraft Electric Propulsion Test Rig ................................................................... 5

Thermal modeling of battery packs................................................................................. 7 


\section{Introduction}

The Center for Renewable Energy and Alternative Transportation Technologies (CREATT) was established to advance the state of the art in knowledge and education on critical technologies that support a renewable energy future. To capitalize on the unique energy landscape in California, the center focused on solar and wind as energy sources and electric vehicles as an emerging transportation system. One key hurdle associated with alternative energies is managing their inherent intermittency. As a result, energy storage technologies are a key component of any renewable energy portfolio, especially those that include: solar, wind, and wave technologies. Energy storage is also a key component of electric transportation systems. Furthermore, with the advent of plug-in hybrids, the use of automotive batteries as ancillary power systems has received increasing attention. As a result, our research and education efforts have focused on alternative energy systems, energy storage systems, and research on battery and hybrid energy storage systems. This report details the Center's progress in the following specific areas:

- Development of a battery laboratory.

- Development of a demonstration system for compressed air energy storage.

- Development of electric propulsion test systems.

- Battery storage systems.

- $\quad$ Thermal management of battery packs.

- Construction of a micro-grid to support real-world performance monitoring of a renewable energy system.

\section{Battery Testing Laboratory}

The Center supported the development of a battery lab to provide applied research and education opportunities for both undergraduate and graduate students in the College of Engineering. This College-wide lab now serves as a key resource for undergraduate laboratories as well as undergraduate and graduate research. Dr. John Dunning developed the lab using undergraduate senior design projects in the Aerospace, Electrical, and Mechanical engineering Departments. The lab is outfitted with automated charging and loading equipment that allows load simulations for stress-testing a broad range of batteries. We have tested batteries ranging from individual AA to $75 \mathrm{~V}$ residential battery packs. A comprehensive battery model has been developed and implemented in MatLab. Dr. Dunning has supplied a Nissan Leaf to support our vision of a comprehensive electric transportation laboratory, and has developed active partnerships with AeroVironment, PG\&E, AC Propulsion and Electricore to support this vision. Currently, the 
Nissan Leaf employs a solar charging system on the campus of Cal Poly to providing a living lab for both instruction and research activities.

\section{Compressed Air Energy Storage}

\section{CAES Study Goals and Current Planned Scope:}

The Compressed Air Energy Storage System (CAES) project was aimed, primarily, at developing an educational tool to demonstrate and evaluate the efficiencies of compressed air energy storage. Though intended as educational, the apparatus we developed can also be used as a research tool to evaluate the role of waste heat recovery, air engine designs, matched engine/generator components, etc.

\section{Test Platform Description:}

The test bed is designed to be a $0.75 \mathrm{~kW}$ output demonstration system. With exception of the storage bank and compressor, all components are mounted on a mobile $4 \mathrm{ft}$ wide $\mathrm{x} 2 \mathrm{ft}$ depth $\mathrm{x} 5 \mathrm{ft}$ tall platform. The primary system components are the compressor, K-bottle storage bank, high and low pressure regulators, air motor, gearing, generator, and adjustable resistor load bank. A data acquisition system and computer are used to monitor system characteristics and determine performance and efficiencies. Instrumentation includes pressure and temperature in 4 locations, compressor power meter, and generator power and voltage meters. The instrumentation data is logged with a National Instruments USB DAQ system and LabView is used to perform real time thermodynamic state determination and efficiency calculations. A Photograph of the system is shown in Figure 1.

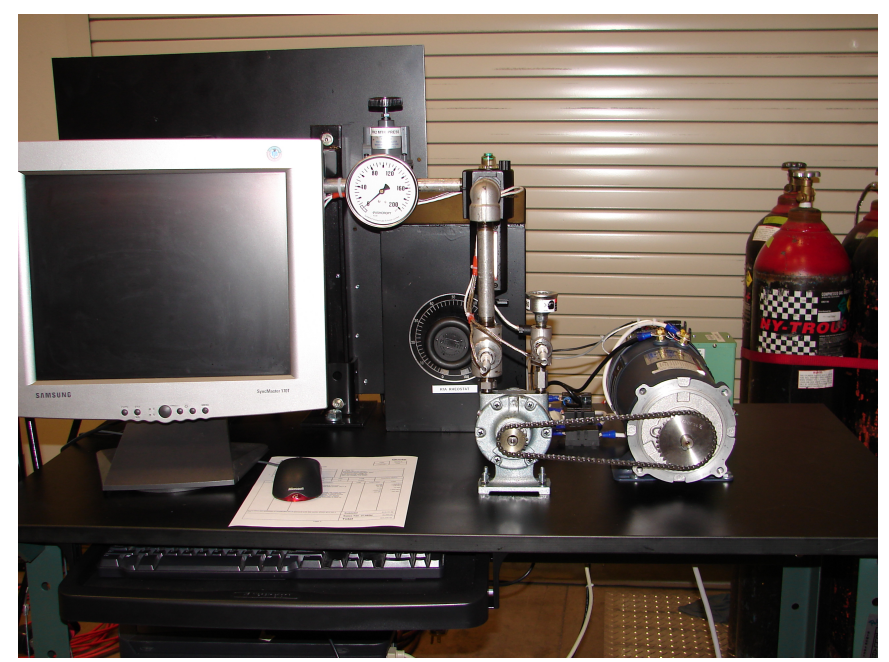

Figure 1. CAES test bed showing data acquisition computer, inlet air regulator, air motor and generator. 


\section{Aircraft Electric Propulsion Test Rig}

The biggest challenge in the design of a general aviation class electric aircraft is in the development of an efficient propulsion system. The central goal of this effort was to assemble and test an electric aircraft propulsion unit. This process involved the purchase of the essential components, followed by the design and fabrication of a test rig that could be used to measure system performance characteristics. Additionally, this test rig was intended for use as a lab exercise for future aerospace engineering students at Cal Poly.

A propulsion unit was purchased from ElectraFlyer that included a DC brushless motor, carbon fiber propeller, charger, controller and lithium polymer batteries. Various components were constructed and purchased in order to fabricate a test rig to support the motor and propeller. Our test stand allows for simultaneous measurement of the torque and thrust of the system through the use of a biaxial sensor. The test rig also measures system voltage and current, which allows the user to determine the discharge profile of the lithium polymer battery pack at various throttle settings. Figures 2 shows the motor and push-propeller mounted within a safety cage, while Figure 3 shows how the sensors are attached to the prop shaft for measurements of torque and thrust. The propeller is a $4 \mathrm{ft}$ diameter, carbon fiber composite, folding pusher powered by a DC brushless permanent magnet electric motor. Electric power is supplied by a $75 \mathrm{~V}, 50 \mathrm{Ah}$ litium ion battery pack made of six sub-packs. Each sub-pack is fabricated from 15 cells; 5 parallel, and those in a series of three. Each cell is $3.7 \mathrm{~V}$ and $10 \mathrm{Ah}$. To assure safety of the students, this system was tested to only $25 \%$ of max power. Torque and shaft output power were measured over a broad range of RPM. By calculating the output power and comparing to power input, one arrives at a system efficiency of $58.6 \%$ under static conditions. Figures 4 and 5 show plots of the experimental measurements of torque, shaft power, and calculated motor efficiency as functions of RPM. This test system was too large to fit inside Cal Poly's 3' $x$ 4' subsonic wind tunnel, limiting these results to static testing that excludes a meaningful inclusion of propeller efficiency. 


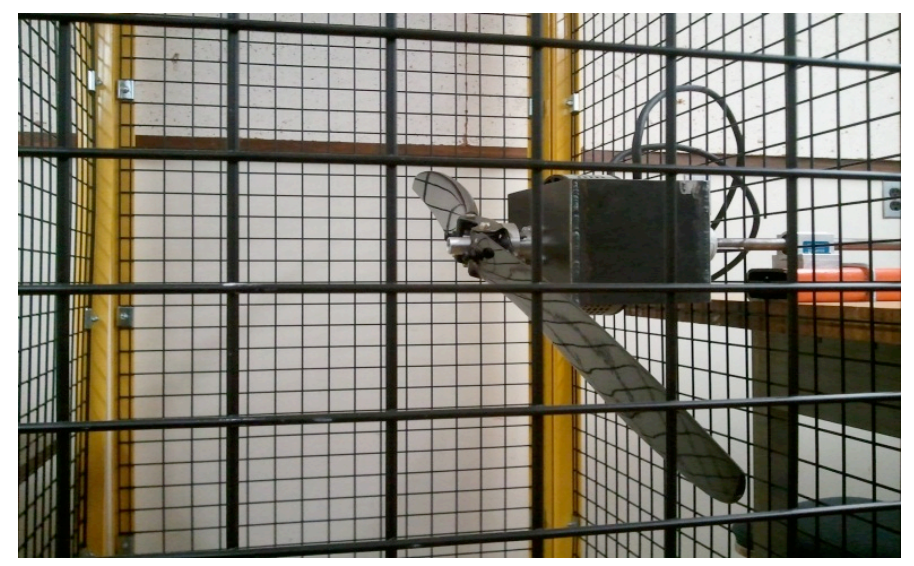

Figure 1: Push propeller used in experiment.

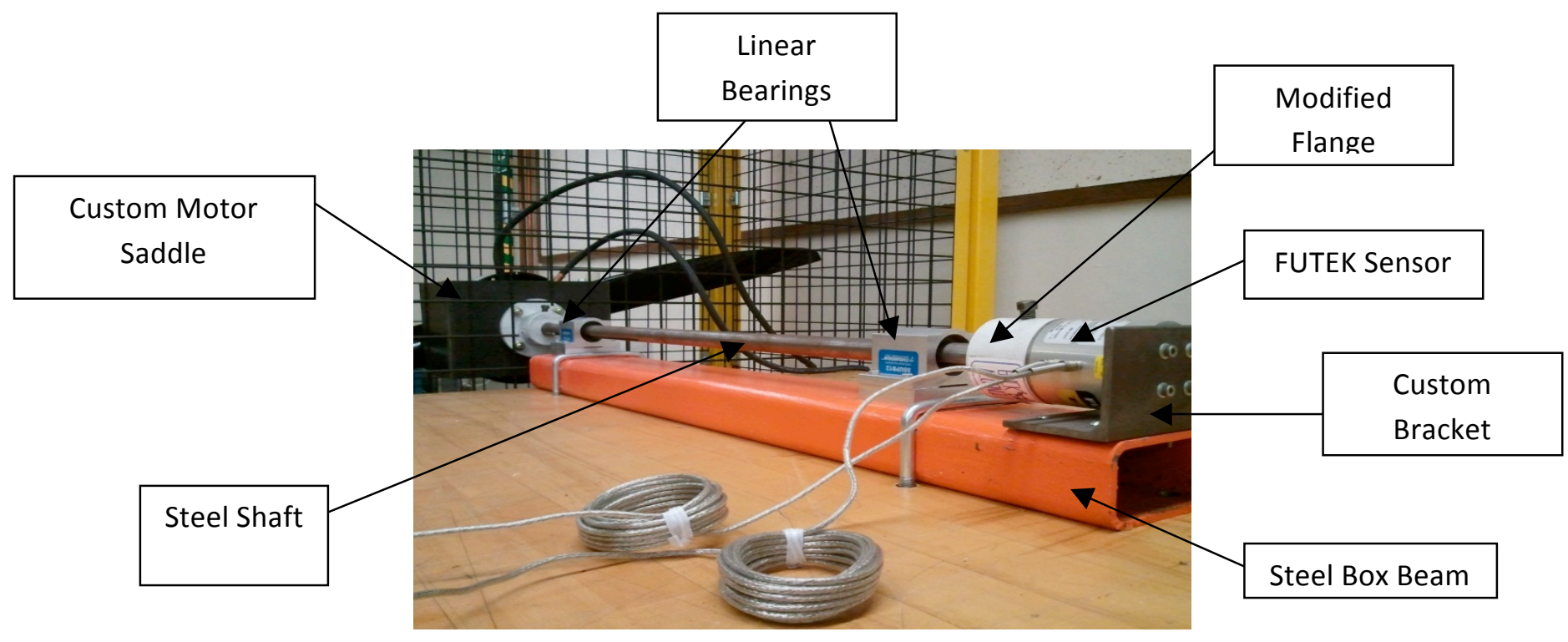

Figure 3: An instrumented shaft was used to measure thrust and torque. 

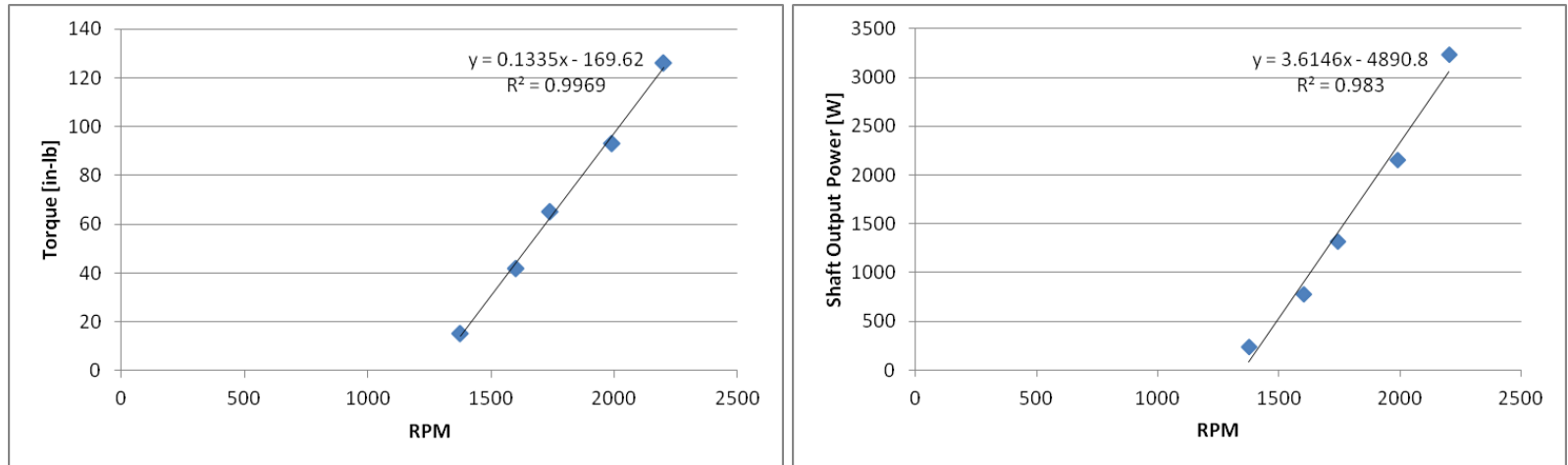

Figure 4: Torque and Shaft Output Power as a function of RPM.

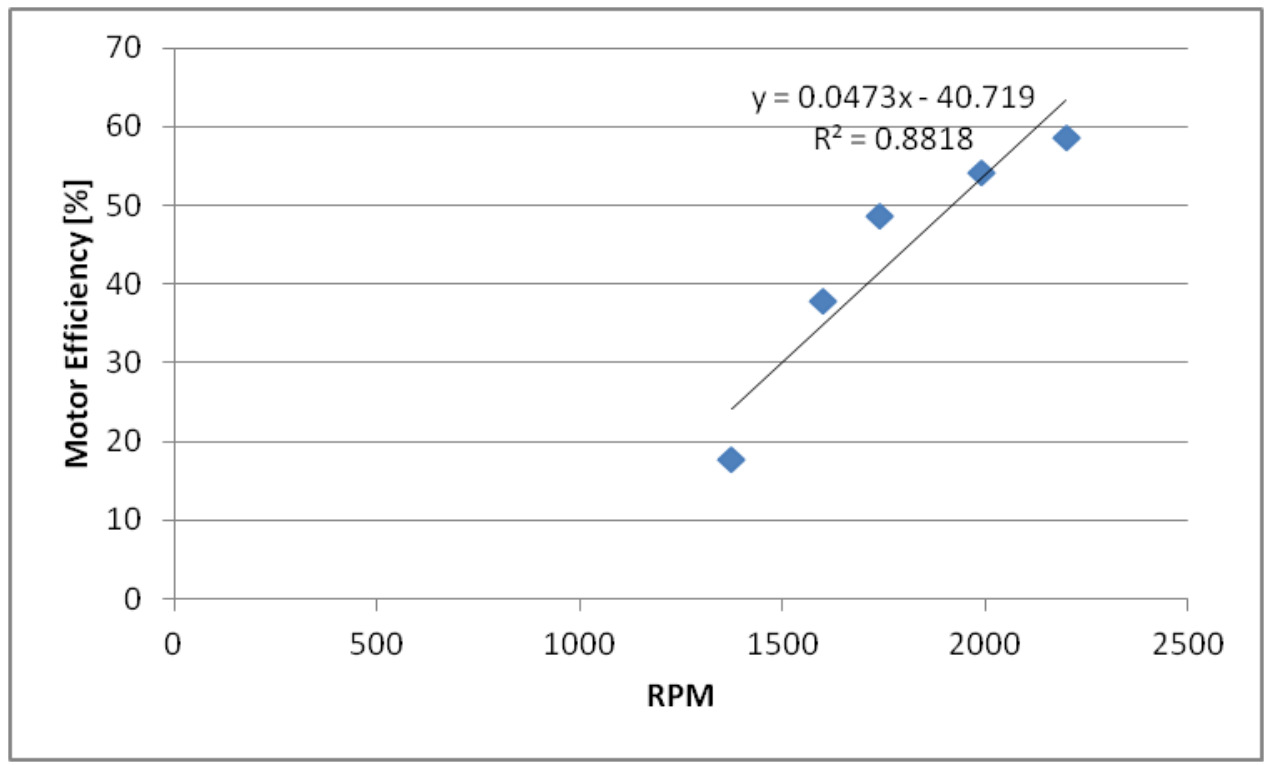

Figure 5: Motor Efficiency as a function of RPM.

\section{Thermal modeling of battery packs}

The transient thermal performance of a lithium-ion battery pack for an unmanned ground vehicle was simulated with ANSYS FLUENT using 1,590,328 tetrahedral elements. The heat generation rates and specific heat capacity were experimentally measured for a 15Ah Headway lithium-ion battery. The battery pack contained fifteen heat generating batteries that were surrounded by an air gap, supported at the top and bottom by two nylon frames, and embedded within a closed aluminum enclosure. A heat generation load was applied to each battery and natural convection film boundary conditions were applied to the exterior of the enclosure. The buoyancy driven flow inside the enclosure was modeled along with the natural convection and radiation heat transfer between internal batteries. The maximum temperature of the batteries reached $72.8 \mathrm{C}$ after 630 seconds of usage at a simulated peak power draw of 85 amps. The batteries exceeded their maximum recommended operating temperature of 
60C. The subject pack was redesigned to utilize a passive thermal management system consisting of a composite expanded graphite matrix with paraffin wax phase change material. The redesigned pack with the passive thermal management system was similarly modeled. The simulation showed that the batteries' maximum temperature reached $51 \mathrm{C}$ after 630 seconds of usage at the simulated peak power load, showing that such a system could keep the batteries below the recommended maximum operating temperature.

A lithium-ion battery pack was designed and built for an unmanned ground vehicle (UGV) using fifteen high capacity lithium iron phosphate (LiFePO4) batteries. These batteries are housed within a closed aluminum container in the shape of a trapezoid, Figure 5. Since the platform is designed to operate outside in rugged and wet terrain, the battery pack must be sealed from the outside environment. Temperature is a concern since the batteries generate a significant amount of heat and the sealed enclosure leads to a substantial temperature rise inside the battery pack. These batteries are designed to operate at a maximum temperature of $60 \mathrm{C}$. Lithium iron phosphate batteries provide the necessary power density required by the UGV, but are known to have high heat generation rates which can limit safe application and battery life. In general, battery packs require cells to be spaced closely together in a confined space, leading to potential temperature excursions that degrade battery life and could lead to thermal runaway. Heat is generated in the cell by two factors; entropy change from electrochemical reactions and from ohmic heating due to current flow across internal resistances. The relative contribution of the reversible heat term is expected to be lower at high charge and discharge rates. Thermal management becomes more critical with larger batteries as surface area to volume decreases with increasing battery size leading to lower heat transfer rates per unit heat generation rate. The goal of this project was to determine the maximum temperatures the batteries would experience under a worst-case loading of $85 \mathrm{~A}$ or $240 \mathrm{~W}$ per battery.

The heat generation rates and specific heat of the battery were measured experimentally using the technique described by A. Mills and S. Al-Hallaj. Following their experimental procedure, one can determine the pertinent material properties to allow measurements of heat generation rates at different current levels. These are expressed in terms of discharge power, where, in the present case, $1 \mathrm{P}=48$ Watts. Results of our experiments allowed us to compare theoretically derived heat generation curves to those measured experimentally, Figure 6. These data show how the heat generation varies with depth-of-discharge (DOD) at different power levels.

In the battery pack studied here, fifteen cylindrical batteries measuring 0.04 meters in diameter and 0.15 meters in height were housed in an aluminum enclosure with a small air gap surrounding them along the sides of the enclosure, Figure 7. A transient analysis was chosen since the simulation reached steady state long after the battery pack would have run out of power. A fixed time step of 0.05 seconds was used to run a 12-minute flow time study. The small time step ensured accuracy of the results and was based on the characteristic time of the modeled system. The Boussinesq approximation was used, which neglects the changes in density of the fluid since they are sufficiently small, except when the density terms appear multiplied by the gravity term. This leads to the conclusion that inertia differences are negligible, but gravity is large enough to make the specific weight changes appreciable to drive buoyancy flow. Figure 8 shows a colored image of the temperature distribution inside the battery pack at a power of 5P after 630 seconds. Figure 9 shows a plot of temperature across the width of the pack through 
the front row of batteries at three different times. This figure shows clearly that the pack temperatures will exceed the recommended operating temperature of $60 \mathrm{C}$.

To improve the thermal performance of the subject pack, a passive thermal management system was designed to mitigate temperature rise in the batteries. This system utilizes a phase changing material (PCM) to store heat without significantly raising the material temperature. The latent heat of fusion of the PCM is utilized to absorb heat energy while melting. Such a passive cooling system allows the battery pack to be fully sealed off from the environment without any intruding cooling elements. As Figure 10 shows, the PCM passive thermal management system modeled here substantially reduced the maximum temperature of the batteries compared to the original pack design. Without passive thermal management, the maximum temperature of the batteries rose beyond the $60 \mathrm{C}$ to roughly $73 \mathrm{C}$. Implementation of a passive thermal management system reduced the maximum temperature of the batteries to $51 \mathrm{C}$, keeping the pack well within the design operating temperature range. 


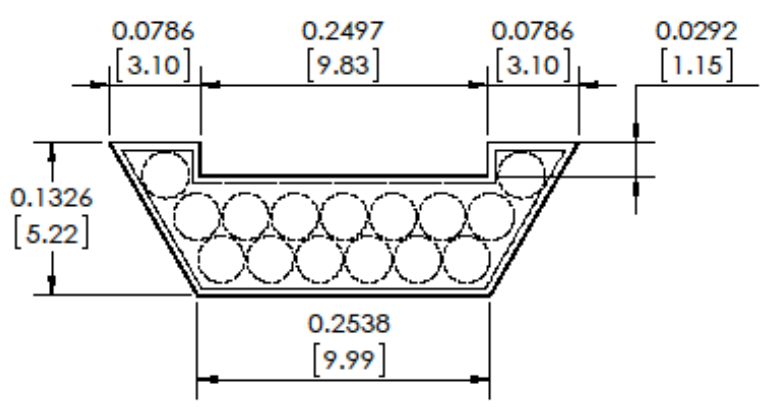

(a)

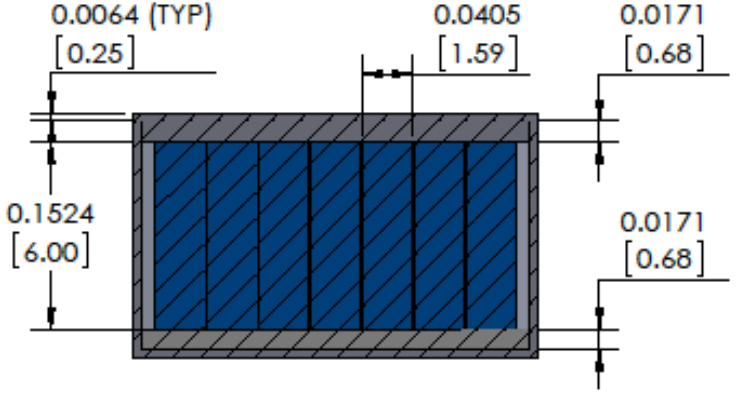

(b)

Figure 5. Section views of battery pack (dimensions in m [in]); (a) top view, (b) side view.

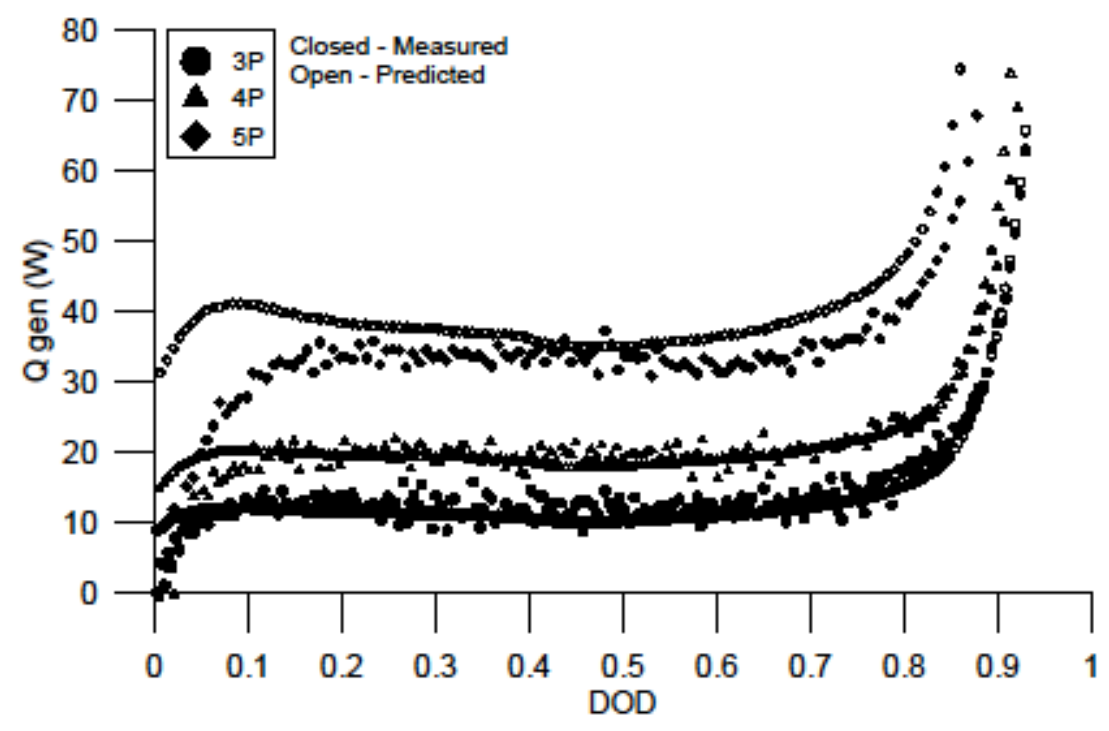

Figure 6: Comparison of measured and predicted heat generation rates (W), at different discharge powers, as a function of depth of discharge. 


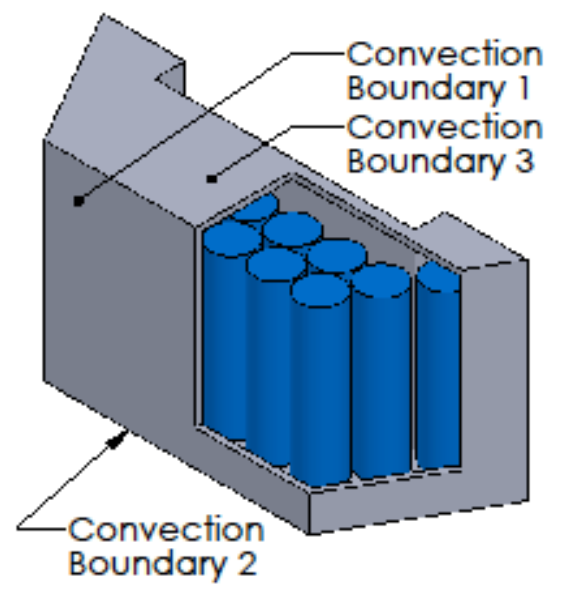

Figure 7: Rendering of the battery pack showing battery packing scheme and package geometry.

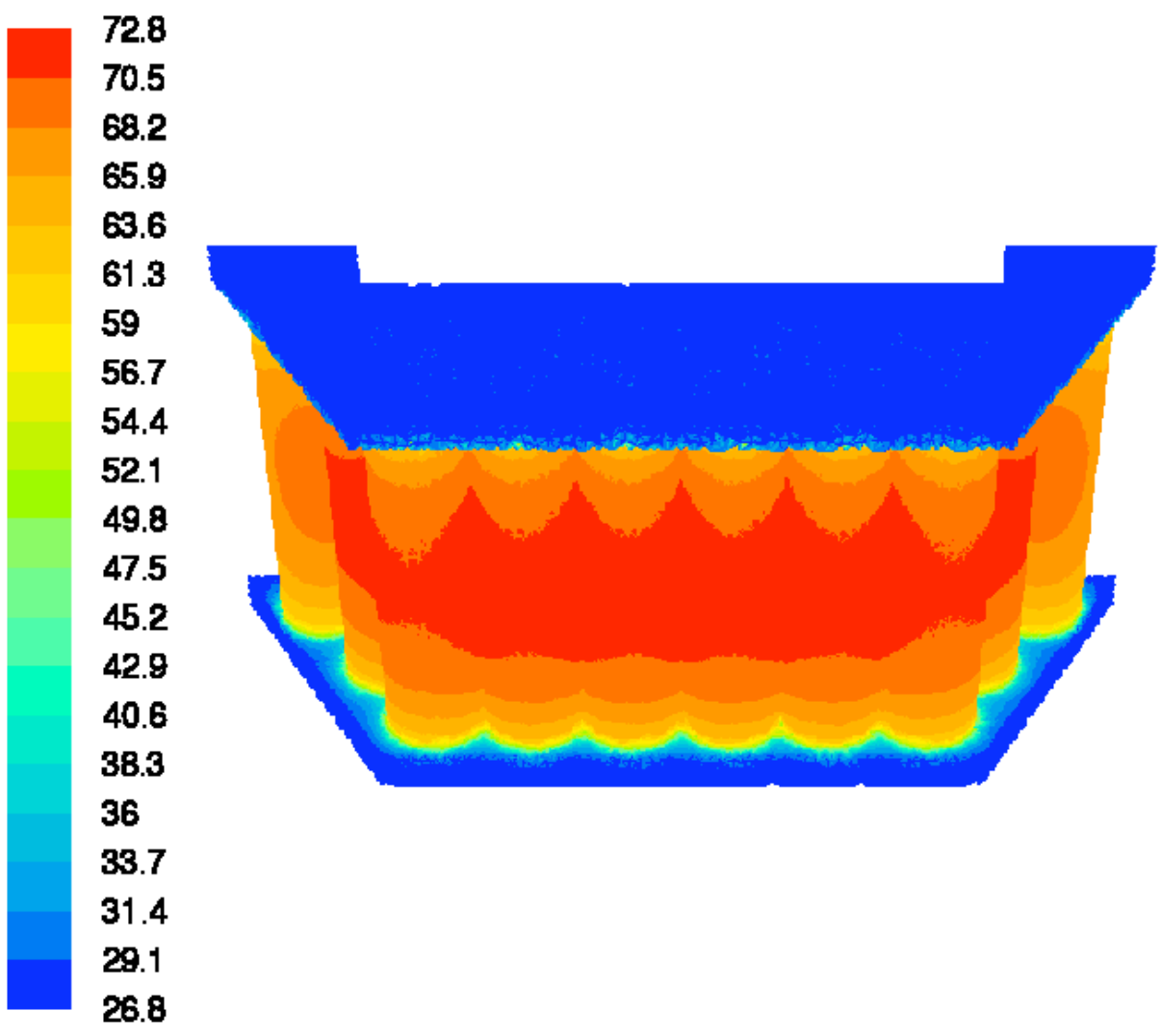

Figure 8: Temperature distribution in the battery pack (degrees $\mathrm{C}$ ) after 630 seconds at $5 \mathrm{P}$. 


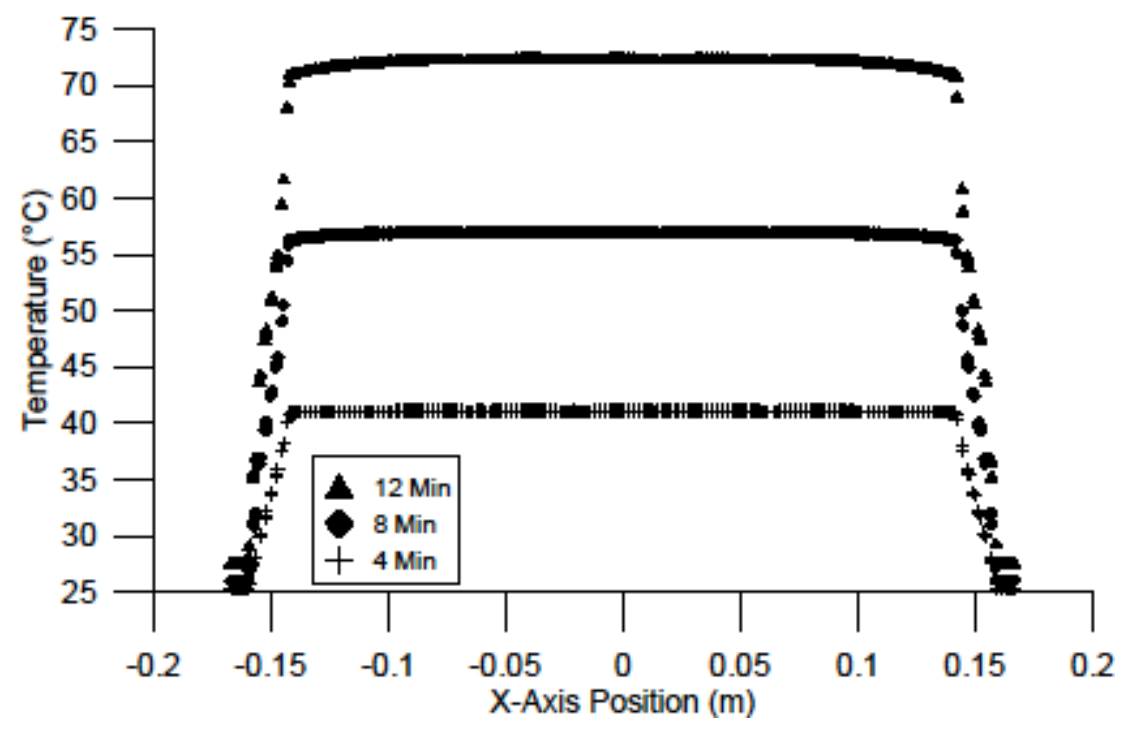

Figure 9: Temperature distribution across the width of the pack in the middle of the front row of batteries for 5P. After 12 minutes the batteries have exceeded their maximum design temperature.

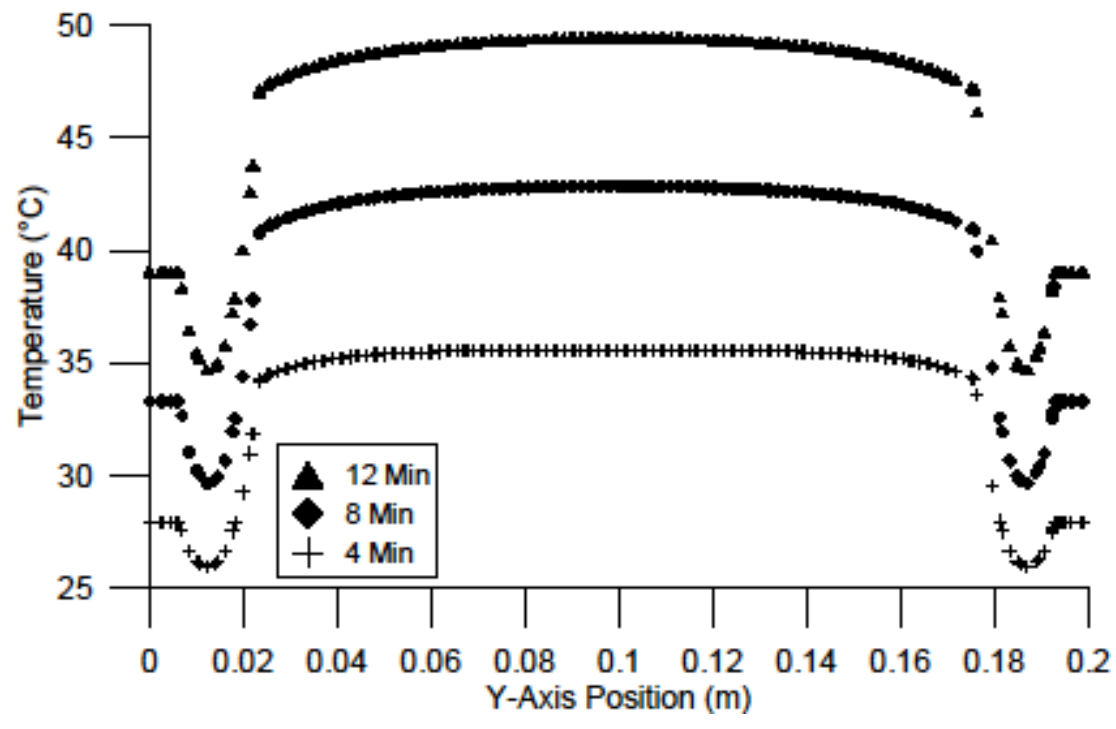

Figure 10: Temperature distribution across the width of the pack, utilizing a passive thermal management system, in the middle of the front row of batteries for $5 \mathrm{P}$. After 12 minutes the maximum battery temperature remains below the design temperature of $60 \mathrm{C}$. 